\title{
Paclitaxel/oxaliplatin/fluorouracil (TOF) regimen versus S-1/ oxaliplatin (SOX) regimen for metastatic gastric cancer patients
}

\author{
Xichao Dai ${ }^{1,2, *}$, Xizhi Zhang ${ }^{1, *}$, Chaomin Wang ${ }^{1}$, Jingting Jiang ${ }^{2}$ and Changping $\mathbf{W u}^{3}$ \\ ${ }^{1}$ Department of Oncology, Subei People's Hospital of Jiangsu Province, Clinical Medical College of Yangzhou University, \\ Jiangsu, Yangzhou, China \\ 2 Department of Tumor Biological Treatment, The Third Affiliated Hospital of Soochow University, Suzhou, China \\ ${ }^{3}$ Department of Oncology, The Third Affiliated Hospital of Soochow University, Suzhou, China \\ * These authors have contributed equally to this work \\ Correspondence to: Chaomin Wang, email: zlydxc@163.com
}

Keywords: paclitaxel; oxaliplatin; fluorouracil; S-1; metastatic gastric cancer

Received: June 13, 2016

Accepted: October 19, 2016

Published:November 30, 2016

Copyright: Dai et al. This is an open-access article distributed under the terms of the Creative Commons Attribution License (CC-BY), which permits unrestricted use, distribution, and reproduction in any medium, provided the original author and source are credited.

\section{ABSTRACT}

Aims and background. This study was designed to compare the efficacy and safety of paclitaxel/oxaliplatin/fluorouracil (TOF) regimen and S-1/oxaliplatin (SOX) regimen for metastatic gastric cancer (GC) patients.

Methods. Sixty patients were divided into TOF group and SOX groups randomly. Patients in the TOF group received paclitaxel $\left(135 \mathrm{mg} / \mathrm{m}^{2}\right.$ iv $)$ on day 1 , oxaliplatin $\left(100 \mathrm{mg} / \mathrm{m}^{2}\right.$ iv) on day 1 , fluorouracil $\left(500 \mathrm{mg} / \mathrm{m}^{2}\right.$ continuous iv) on day $1-5$. The patients in the SOX group received oxaliplatin $\left(130 \mathrm{mg} / \mathrm{m}^{2}\right.$ iv) on day 1 and S-1 (40 mg 60mg orally twice/day based on body surface area) on days 1-14. All the treatments were repeated every 21d for 4-6 cycles.

Results. The ORR and DCR of TOF group was $43.3 \%$ and $60.0 \%$, respectively while that of SOX group was $36.7 \%$ and $56.7 \%$. There were no statistical differences between the ORRs $\left(x^{2}=0.278\right)$ and the DCRs $\left(x^{2}=0.069\right)$ of the 2 groups. The majority of adverse events of two groups were hematological and digestive ones. Most of them were grade I and II. The adverse event rate of TOF group was higher than SOX group. The PFS times of TOF and SOX groups were 6.5 and 5.8 months, respectively. There was no statistical difference between the PFSs of the 2 groups $(P=0.451)$.

Conclusions. The efficacies of TOF and SOX regimens are similar but the safety of SOX regimen better than TOF regimen.

\section{INTRODUCTION}

Gastric cancer occupies the second place of deaths caused by malignances over the world and It is especially popular in Asia [1-3],which is the third common carcinoma in China [4]. and the incidence rate and death rate of gastric cancer in Jiangsu Province are especially higher than the national average [5].

Surgical resection is the preferred treatment for gastric cancer, but approximately two-thirds of patients have metastatic disease at the time of diagnosis [6]. Prognosis in these patients is adverse. Median survival time of them is 3 to 5 months without treatment [7] while 5-year survival rate is reported as 9.4\% [8]..Local recurrence and distant metastasis occur in $60 \%$ of mGC patients even with a radical stomach surgery [9]

Chemotherapy is the most effective treatment option for patients with advanced gastric cancer who can't be operated on [10-12].and the efficacy of postoperative chemotherapy has been acknowledged [13]. However, a worldwide consensus on standard chemotherapy regimens has yet to be established. The prognosis has gradually improved because of advances in chemotherapy regimens, but is not yet satisfactory.

Among various regimens, the combinations of paclitaxel/oxaliplatin/fluorouracil (TOF) regimen and S-1/ oxaliplatin (SOX) regimen have become two important ones. 
. As we all knew,the combination of Docetaxel / cisplation/ fluorouracil (DCF) had been verified by V325 trail to have higher RR, TTP, OS than FP4W [14]..

Oxaliplatin is the third generation of diaminocyclohexane platinum compounds with broad spectrum antitumor activity, which is better safety than cisplatin [13, 15].Paclitaxel is another Taxanes besides Docetaxel which can induce hyperstabilization of microtubules resulting in cell cycle arrest and apoptosis $[16,17]$. The objective response rate of patients with gastric cancer to paclitaxel is $20 \%-25 \%$ [18]. So We assumpt that the combination of paclitaxel/oxaliplatin/ fluorouracil (TOF) regimen may substitute for DOF with lower toxicity.

S-1 is an oral anti-cancer drug of modified Fluorouracil composed of oteracil potassium, 5-chloro2,4-dihydroxypy-ridine, tegafur [19],. which was also demonstrated to be not inferior to intravenous infusion of 5 -FU when both were administered as a single drug [20, 21]. Combination of cisplatin with $\mathrm{S}-1(\mathrm{CS})$ is considered as standard first-line chemotherapy regimen for metastatic gastric cancer by SPIRIT trail in Japan [21, 22].

The applying of S-1 as adjuvant chemotherapy for $\mathrm{mGC}$ can improve the overall survival (OS) and relapsefree survival [23].

$\mathrm{OS}$ in $\mathrm{mGC}$ was proven to benefit from S-1 based chemotherapy rather than 5-FU-based chemotherapy in a metal-analysis [3, 24]. Combination of S-1 with oxaliplatin(SOX) was demonstrated not to inferior to $\mathrm{S} 1$ plus cisplatin(CS) in PFS. SOX regimen also had well tolerance in patients with $\mathrm{mGC}$ [25].From this , $\mathrm{SOX}$ is thought as a new first-line treatment choice of $\mathrm{mGC}$ in Asia, especially in China and Japan [21].

But, What is the activity of combinations of paclitaxel/oxaliplatin/fluorouracil (TOF) regimen in $\mathrm{mGC}$ ?

It is well known that only one regimen is optimal at one time. UP to now, There is no study comparing efficacy and safety of SOX and TOF.So, This randomized and controlled study was performed to compare efficacy and safety of two regimen in $\mathrm{mGC}$ patients .

\section{PATIENTS AND METHODS}

\section{Patients}

This study was approved by the ethics committees of all participating medical institutions and conducted according to the principles of the Declaration of Helsinki and Good Clinical Practice Guidelines. Between Feb. 2012 and Jan. 2014, a total of 60 patients bearing mGC were enrolled. All patients gave their written informed consent before enrollment.

The inclusion criteria were 1) pathologically confirmed mGC (stage IV), 2) ages between 20 and 80 years, 3) measurable or assessable lesions by imaging studies according to the RECIST guideline [26], 4) no prior chemotherapy except for postoperative adjuvant chemotherapy for more than 12 months before entry into the study, 5) Eastern Cooperative Oncology Group (ECOG) performance status score less than 3,6) hepatic function (total bilirubin $\leq 1.5 \times$ the institutional upper limit of normal value, aspartate aminotransferase/ alanine aminotransferase $\leq 2.5 \times$ the institutional upper limit of normal value, and alkaline phosphatase $\leq 2.5 \times$ the institutional upper limit of normal value), renal function (serum creatinine level $\leq 1.5 \mathrm{mg} / \mathrm{dL}$ and creatinine clearance $\geq 50 \mathrm{ml} / \mathrm{min}$ ) and adequate bone marrow function (hemoglobin level $\geq 90 \mathrm{~g} / \mathrm{L}$, white blood cell count of $4-10 \times 10^{9} / \mathrm{L}$, neutrophil count $\geq 2 \times 10^{9} / \mathrm{L}$, and platelet count $\geq 100 \times 10^{9} / \mathrm{L}$ ), and 7) estimated life expectancy more than 3 months and 8) no other secondary malignant tumors.

The exclusion criteria were 1) preexisted peripheral toxicity $\geq$ grade 2 of the National Cancer Institute Common Toxicity Criteria, 2) concurrent or prior malignancy, 3) central nervous system metastases, 4) concurrent treatment that interfered with the study evaluation, 5) active infection, 6) other uncontrolled underlying medical conditions that would impair the ability of the patients to receive the planned treatment, 7) having inadequate calorie and fluid intake, and 8) pregnant, and breastfeeding women or women of childbearing potential without adequate contraception.

\section{Treatment}

The patients were divided into TOF group and SOX groups randomly. Patients in the TOF group received paclitaxel $\left(135 \mathrm{mg} / \mathrm{m}^{2}\right.$ iv) on day 1 , oxaliplatin (100 $\left.\mathrm{mg} / \mathrm{m}^{2} \mathrm{iv}\right)$ on day 1 , fluorouracil $\left(500 \mathrm{mg} / \mathrm{m}^{2}\right.$ continuous iv) on day 1-5. The patients in the SOX group received oxaliplatin $\left(130 \mathrm{mg} / \mathrm{m}^{2} \mathrm{iv}\right)$ on day 1 and S-1 (40 mg twice/ day for body surface area $<1.25 \mathrm{~m}^{2}$ and $60 \mathrm{mg}$ twice/day for body surface area between 1.25 and $1.50 \mathrm{~m}^{2}$ orally) on days $1-14$. All the treatments were repeated every $21 \mathrm{~d}$ for 4-6 cycles.

The dose was modified based on the hematologic parameters and the degree of non-hematologic toxicities. The dose was modified for the TOF group as following, 1) if the hepatotoxicity reached grade 2 or more, the dose of paclitaxel for the following treatment was reduced to $100 \mathrm{mg} / \mathrm{m}^{2}$ on days 1 ; if the hepatotoxicity was grade $3 / 4$, the study was discontinued. (2) If the bone marrow suppression reached grade 4 , the dose of paclitaxel for the following cycle was reduced to $100 \mathrm{mg} / \mathrm{m}^{2}$ on day 1 ; if the bone marrow suppression reached grade 4 , the study was discontinued; 3 ) if the mucositis reached grade 3/4, fluorouracil was administered from the next cycle for only 3 days; 4) if the creatinine clearance rate decreased 
Table 1: Patients baseline characteristics $(n=60)$

\begin{tabular}{|c|c|c|c|}
\hline \multirow{2}{*}{ Characteristics } & \multicolumn{2}{|l|}{ Patients (\%) } & \multirow{2}{*}{$P$} \\
\hline & TOF $(n=30)$ & $\operatorname{SOX}(n=30)$ & \\
\hline Sex & & & 0.785 \\
\hline Female & 9 & 11 & \\
\hline Male & 21 & 19 & \\
\hline Age (years) & & & 0.787 \\
\hline Median & 58 & 57 & \\
\hline Range & $21-73$ & $20-75$ & \\
\hline Histologic type & & & 0.757 \\
\hline Adenocarcinoma & 22 & 21 & \\
\hline Adenosquamous carcinoma & 5 & 7 & \\
\hline Mucinous carcinoma & 3 & 2 & \\
\hline No. of metastatic lesion & & & 0.771 \\
\hline $0-1$ & 7 & 9 & \\
\hline$\geq 2$ & 23 & 21 & \\
\hline Prior adjuvant chemotherapy & & & 1.000 \\
\hline No & 18 & 18 & \\
\hline Yes & 12 & 12 & \\
\hline
\end{tabular}

to $30-50 \mathrm{~mL} / \mathrm{min}$ resulted by the nephrotoxicity, the dose of oxaliplatin was reduced by $50 \%$; if the creatinine clearance rate was lower than $30 \mathrm{~mL} / \mathrm{min}$, the study was discontinued.

The dose was modified for the SOX group as following: 1) if the neurotoxic toxicity was grade $1 / 2$, the dose of oxaliplatin was reduced by $25 \% ; 2$ ) if the neurotoxic toxicity was grade $3 / 4$ or persistent, the oxaliplatin was omitted from the regimen until the neurotoxic toxicity was resolved to grade 1 or better.

\section{Evaluation}

The outcomes of electrocardiogram, computed tomography (CT) scan, and levels of tumor markers (CA19-9, CA72-4, CA24-2 and carcinoembryonic antigen) were obtained from the patients within $7 \mathrm{~d}$ after enrollment. Hematology tests, biochemistry tests, and assessment of symptoms and signs were carried out for the patients within 3 days before enrollment and every week during the study period. CT scans were carried out and levels of tumor markers were measured before each cycle. According to the RECIST guideline [16], responses concluded complete response (CR), partial response (PR), stable disease (SD), and progressive disease (PD). To confirm the PR or CR, the levels of tumor markers were measured no less than 4 weeks after the objective response was obtained. Responses were assessed by the independent review committee. The overall response rate (ORR) was defined as the sum of CR and PR rates. The disease controlled rate (DCR) was defined as the sum of CR, PR and SD rates. Safety was evaluated according to the NCICTC. PFS is defined as the time from randomization until objective tumor progression or death.
PFS is primary endpoint of our study .The secondary endpoint is ORR, DCR.

\section{Statistical analysis}

Statistical analysis was performed with the SPSS software (version 17.0, SPSS). Chi-square test was used to compare the categorical data. $P<0.05$ was considered statistically significant.

\section{RESULTS}

\section{Patient baseline characteristics}

The patient baseline characteristics are listed in Table 1. The difference between two groups was not statistically significant in any characteristics..

\section{ORR and DCR}

The patients all received 4-6 cycles of chemotherapy and were suitable for response evaluation.

No patients developed severe adverse events leading to exclusion of the efficacy analysis.

Among the patients in TOF group, 1 achieved a CR, 12 achieved a PR, 5 achieved a SD, and 12 achieved a PD, with an ORR of $43.3 \%$ and a DCR of $60.0 \%$.

Among the patients in SOX group, 1 achieved a CR, 10 achieved a PR, 6 achieved a SD, and 13 achieved a PD, with an ORR of $36.7 \%$ and a DCR of $56.7 \%$. There were no statistical differences between the ORRs $\left(\chi^{2}=0.278\right)$ 
Table 2: Objective response of TOF and SOX groups, $n(\%)$

\begin{tabular}{|c|c|c|c|c|c|c|c|c|}
\hline Group & CR & PR & SD & PD & & RR & & DCR \\
\hline TOF $(n=30)$ & $1(3.3)$ & $12(40.0)$ & $5(16.7)$ & $12(40.0)$ & $24(80.0)$ & \multirow{2}{*}{$\begin{array}{l}P=0.243 \chi^{2} \\
=1.367\end{array}$} & $18(60.0)$ & \multirow{2}{*}{$\begin{array}{l}P=0.793 \\
\chi 2=0.069\end{array}$} \\
\hline $\operatorname{SOX}(n=30)$ & $1(3.3)$ & $10(33.3)$ & $6(20.0)$ & $13(43.3)$ & $20(66.7)$ & & $17(56.7)$ & \\
\hline
\end{tabular}

Table 3: Adverse events of TOF and SOX groups, $n(\%)$

\begin{tabular}{|l|c|c|c|c|}
\hline \multirow{2}{*}{\multicolumn{1}{c|}{ Toxicity }} & \multicolumn{2}{c|}{ TOF } & \multicolumn{2}{c|}{ SOX } \\
\cline { 2 - 5 } & I - II & III - IV & I - II & III - IV \\
\hline WBC decreasing & 27 & 2 & 12 & 0 \\
\hline Neutrophil decreasing & 26 & 2 & 10 & 0 \\
\hline Anemia & 1 & 0 & 1 & 0 \\
\hline PLT decreasing & 8 & 0 & 5 & 0 \\
\hline Diarrhea & 10 & 0 & 2 & 0 \\
\hline Vomiting & 19 & 2 & 10 & 0 \\
\hline Alopecia & 28 & 0 & 5 & 0 \\
\hline Oral mucositis & 12 & 0 & 2 & 0 \\
\hline Hand-foot syndrome & 7 & 0 & 5 & 0 \\
\hline Neurotoxicity & 6 & 0 & 5 & 0 \\
\hline
\end{tabular}

WBC: white blood cell; PLT: platelet

and the DCRs $\left(\chi^{2}=0.069\right)$ of the 2 groups. See Table 2 .

In TOF group, the efficacy of the 1 patient was evaluated as CR, 12 patients was evaluated as PR. 5 patients was evaluated as SD, 12 patients was evaluated as PD. The ORR was $43.3 \%$ with a DCR of $60.0 \%$. In SOX group, the efficacy of the 1 patient was evaluated as CR, 10 patients was evaluated as PR. 6 patients was evaluated as SD, 13 patients was evaluated as PD. The ORR was $36.7 \%$, with a DCR of $56.7 \%$. There were no statistical differences between the ORRs $\left(\chi^{2}=0.278\right)$ and the DCRs $\left(\chi^{2}=0.069\right)$ of the 2 groups. See Table 2 .

\section{Safety}

No patient discontinued or ended the treatment due to intolerable adverse events. The majority of adverse events of both the 2 groups were hematological and digestive ones. Most of them were grade I and II and grade III and IV hematological adverse events were also observed. Generally, the adverse event rate of TOF group was higher than SOX group. There were no statistical differences between the grade III and IV adverse events the 2 groups. And basically the adverse events relieved after symptomatic treatment. See Table 3.

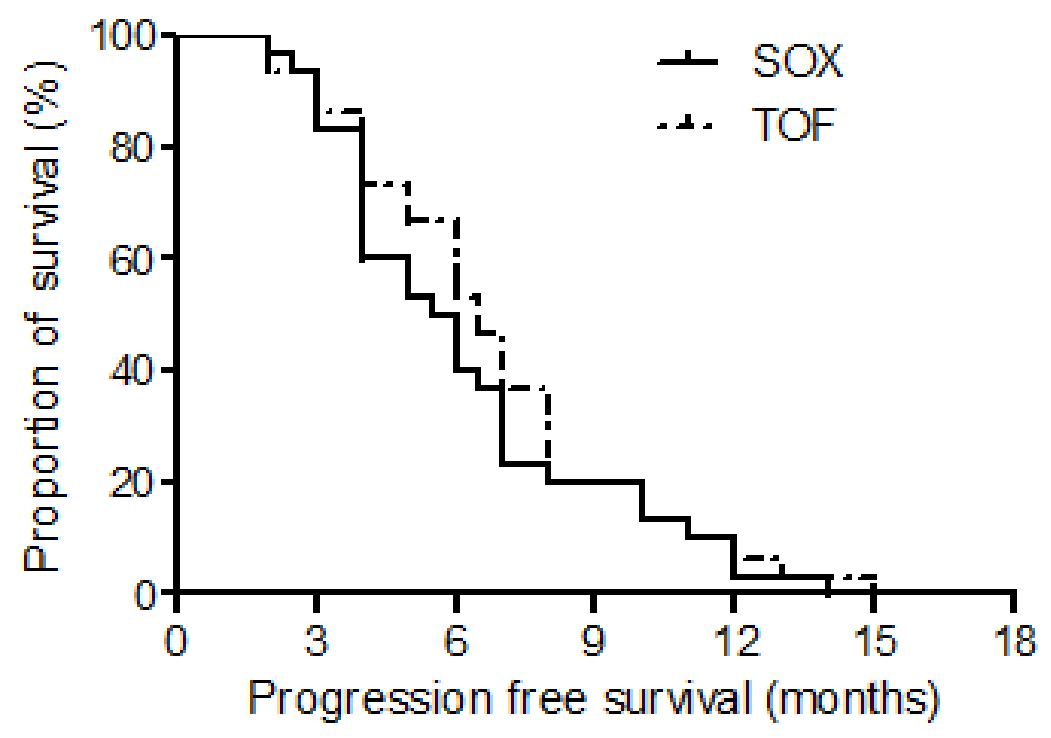

Figure 1: The progression free survival curves of the TOF and SOX groups. There is no statistical difference between the progression free survival times of the 2 groups. 


\section{Progression free survival (PFS)}

The PFS times of TOF and SOX groups were 6.5 and 5.8 months, respectively. There is no statistical difference between the PFSs of the 2 groups $(P=0.451)$. See Figure 1.

\section{DISCUSSION}

Chinese gastric cancer patients are oftern diagnosed at later stage with distant metastases [27] Although there are many treatment modality such as operation combined with chemotherapy which can be used to treat gastric cancer $[28,29]$, there is currently no standard regimen for $\mathrm{mGC}$ patients. Therefore, it is urgent to obtain a new therapeutic strategy with better efficacy and tolerable toxicity. In the present study, SOX regimen is usually considered to be the first-line therapy choice for mGC in China [30] and Japan [31] TOF regimen is not that widely applied. V325 trail has proven the ORR(36.7\%), TTP $(5.6 \mathrm{~m})$ of DCF regimen, docetaxel/cisplatin/ fluorouracil, higher than FP4w [14].It can be chose as firstline regimen for $\mathrm{mGC}$ but for high toxicity.

Following promising phase II study results [32], [33, 34], oxaliplatin was verified to have the non-inferiority compared with cisplatin with low toxicity. As we all know Paclitaxel is another taxane which has been used widely in $\mathrm{mGC}$.

So We assumpted that TOF may substitute for DCF with tolerable side effect.

The efficacy and safety of TOF and SOX regimen were discovered in $\mathrm{mGC}$. We found that the therapeutic efficacies of the 2 groups were similar but SOX regimen seemed to have lower toxicity than TOF regimen.

Different combination chemotherapy regimens as first-line therapy demonstrated median PFS of 5-6 months and response rate of $35-45 \%$ [35].

Our data on antitumor response basically meet with this range and we gained a slightly longer PFS.

There are few articles focusing on TOF in $\mathrm{mGC}$, which is possible due to the consideration of the adverse events of this regimen. Actually our results do confirm this consideration.

We did not report the outcome of overall survival of the patients due to the 5-year follow-up has not been finished. And there is no statistical difference between Progression free survival times of the 2 groups. However, we can still find the tendency of longer survival time of TOF regimen. The survival outcome needs to be clarified by studies with larger sample sizes.

Several recent clinical trails have shown that SOX regimen is a effective and easily tolerated treatment method for mGC patients [12, 31, 36, 37].

The response rates of SOX for $\mathrm{mGC}$ range from $53.7 \%$ to $59.0 \%$ [12, 31, 37, 38]. Besides, Koizumi et al.
[31] reported the median PFS time of patients receiving SOX regimen was 6.5 months and the incidence of grade $3 / 4$ toxicity was lower. Similarly, Oh et al. [37] and Liu et al. [30] also showed that the SOX regimen was easily tolerated and more convenient treatment as a first-line therapy for mGC patients. All these results met ours.

Moreover, the development of adverse events had worse outcomes than the patients who did not experience adverse events, suggesting that the frequency of adverse events is an important factor in evaluating the efficacy of the drug [39].

Conclusively, we demonstrated that the therapeutic efficacies of TOF regimen and SOX regimen are similar but the safety of SOX regimen is more tolerable than TOF regimen. Hence, we would rather recommend SOX regimen for mGC patients not only because of the acceptable benefits to the efficacy and PFS but more importantly the better safety. Further studies are guaranteed to corroborate the result of this study.

\section{CONFLICTS OF INTEREST}

There is no conflict of interest.

\section{REFERENCES}

1. Siegel R, Ma J, Zou Z, Jemal A. Cancer statistics, 2014. CA Cancer J Clin. 2014; 64: 9-29. doi: 10.3322/caac.21208.

2. Kamangar F, Dores GM, Anderson WF. Patterns of cancer incidence, mortality, and prevalence across five continents: defining priorities to reduce cancer disparities in different geographic regions of the world. J Clin Oncol. 2006; 24: 2137-50. doi: 10.1200/JCO.2005.05.2308.

3. He MM, Wu WJ, Wang F, Wang ZQ, Zhang DS, Luo HY, Qiu MZ, Wang FH, Ren C, Zeng ZL, Xu RH. S-1-based chemotherapy versus capecitabine-based chemotherapy as first-line treatment for advanced gastric carcinoma: a metaanalysis. PLoS One. 2013; 8: e82798. doi: 10.1371/journal. pone. 0082798 .

4. Zhao P, Dai M, Chen W, Li N. Cancer trends in China. Jpn J Clin Oncol. 2010; 40: 281-5. doi: 10.1093/jjco/hyp187.

5. Shen X, Zhang J, Yan Y, Yang Y, Fu G, Pu Y. Analysis and estimates of the attributable risk for environmental and genetic risk factors in gastric cancer in a Chinese population. J Toxicol Environ Health A. 2009; 72: 759-66.

6. Vanhoefer U, Rougier P, Wilke H, Ducreux MP, Lacave AJ, Van Cutsem E, Planker M, Santos JG, Piedbois P, Paillot B, Bodenstein H, Schmoll HJ, Bleiberg H, et al. Final results of a randomized phase III trial of sequential highdose methotrexate, fluorouracil, and doxorubicin versus etoposide, leucovorin, and fluorouracil versus infusional fluorouracil and cisplatin in advanced gastric cancer: A trial of the European Organization for Research and Treatment of Cancer Gastrointestinal Tract Cancer Cooperative Group. J Clin Oncol. 2000; 18: 2648-57. 
7. Glimelius B, Ekstrom K, Hoffman K, Graf W, Sjoden PO, Haglund U, Svensson C, Enander LK, Linne T, Sellstrom H, Heuman R. Randomized comparison between chemotherapy plus best supportive care with best supportive care in advanced gastric cancer. Ann Oncol. 1997; 8: 163-8.

8. Imamura Y, Yoshimi I. Comparison of Cancer Mortality (Stomach Cancer) in Five Countries: France, Italy, Japan, UK and USA from the WHO Mortality Database (19602000). Jpn J Clin Oncol. 2005; 35: 103-5. doi: 10.1093/jjco/ hyi030.

9. Rivera F, Vega-Villegas ME, Lopez-Brea MF. Chemotherapy of advanced gastric cancer. Cancer Treat Rev. 2007; 33: 315-24. doi: 10.1016/j.ctrv.2007.01.004.

10. Wagner AD, Grothe W, Haerting J, Kleber G, Grothey A, Fleig WE. Chemotherapy in advanced gastric cancer: a systematic review and meta-analysis based on aggregate data. J Clin Oncol. 2006; 24: 2903-9. doi: 10.1200/ jco.2005.05.0245.

11. Murad AM, Santiago FF, Petroianu A, Rocha PR, Rodrigues MA, Rausch M. Modified therapy with 5-fluorouracil, doxorubicin, and methotrexate in advanced gastric cancer. Cancer. 1993; 72: 37-41.

12. Xu R, Ma N, Wang F, Ma L, Chen R, Chen R, Kebinu M, Ma L, Han Z, Ayixiamu, Mayier M, Su P, Naman Y, et al. Results of a randomized and controlled clinical trial evaluating the efficacy and safety of combination therapy with Endostar and S-1 combined with oxaliplatin in advanced gastric cancer. Onco Targets Ther. 2013; 6: 9259. doi: $10.2147 /$ ott.s46487.

13. Di Francesco AM, Ruggiero A, Riccardi R. Cellular and molecular aspects of drugs of the future: oxaliplatin. Cell Mol Life Sci. 2002; 59: 1914-27.

14. Ajani JA, Moiseyenko VM, Tjulandin S, Majlis A, Constenla M, Boni C, Rodrigues A, Fodor M, Chao Y, Voznyi E, Marabotti C, Van Cutsem E. Clinical benefit with docetaxel plus fluorouracil and cisplatin compared with cisplatin and fluorouracil in a phase III trial of advanced gastric or gastroesophageal cancer adenocarcinoma: the V-325 Study Group. J Clin Oncol. 2007; 25: 3205-9. doi: 10.1200/jco.2006.10.4968.

15. Eriguchi M, Nonaka Y, Yanagie H, Yoshizaki I, Takeda Y, Sekiguchi M. A molecular biological study of antitumor mechanisms of an anti-cancer agent Oxaliplatin against established human gastric cancer cell lines. Biomed Pharmacother. 2003; 57: 412-5.

16. Schiff PB, Fant J, Horwitz SB. Promotion of microtubule assembly in vitro by taxol. Nature. 1979; 277: 665-7. doi:

17. Ganansia-Leymarie V, Bischoff P, Bergerat JP, Holl V. Signal transduction pathways of taxanes-induced apoptosis. Curr Med Chem Anticancer Agents. 2003; 3: 291-306.

18. Levi F, Misset JL, Brienza S, Adam R, Metzger G, Itzakhi M, Caussanel JP, Kunstlinger F, Lecouturier S, Descorps-Declere A, Jasmin C, Bismuth H, Reinberg A. A chronopharmacologic phase II clinical trial with 5-fluorouracil, folinic acid, and oxaliplatin using an ambulatory multichannel programmable pump. High antitumor effectiveness against metastatic colorectal cancer. Cancer. 1992; 69: 893-900.

19. Shirasaka T, Shimamato Y, Ohshimo H, Yamaguchi M, Kato T, Yonekura K, Fukushima M. Development of a novel form of an oral 5-fluorouracil derivative (S-1) directed to the potentiation of the tumor selective cytotoxicity of 5-fluorouracil by two biochemical modulators. Anticancer Drugs. 1996; 7: 548-57.

20. Boku N, Yamamoto S, Fukuda H, Shirao K, Doi T, Sawaki A, Koizumi W, Saito H, Yamaguchi K, Takiuchi H, Nasu J, Ohtsu A. Fluorouracil versus combination of irinotecan plus cisplatin versus S-1 in metastatic gastric cancer: a randomised phase 3 study. Lancet Oncol. 2009; 10: 10639. doi: 10.1016/s1470-2045(09)70259-1.

21. Lordick F, Lorenzen S, Yamada Y, Ilson D. Optimal chemotherapy for advanced gastric cancer: is there a global consensus? Gastric Cancer. 2014; 17: 213-25. doi: 10.1007/ s10120-013-0297-z.

22. Koizumi W, Narahara H, Hara T, Takagane A, Akiya T, Takagi M, Miyashita K, Nishizaki T, Kobayashi O, Takiyama W, Toh Y, Nagaie T, Takagi S, et al. S-1 plus cisplatin versus S-1 alone for first-line treatment of advanced gastric cancer (SPIRITS trial): a phase III trial. Lancet Oncol. 2008; 9: 215-21. doi: 10.1016/s14702045(08)70035-4.

23. Sasako M, Sakuramoto S, Katai H, Kinoshita T, Furukawa H, Yamaguchi T, Nashimoto A, Fujii M, Nakajima T, Ohashi Y. Five-year outcomes of a randomized phase III trial comparing adjuvant chemotherapy with S-1 versus surgery alone in stage II or III gastric cancer. J Clin Oncol. 2011; 29: 4387-93. doi: 10.1200/jco.2011.36.5908.

24. Huang J, Cao Y, Wu L, Liao C, He Y, Gao F. S-1-based therapy versus 5-FU-based therapy in advanced gastric cancer: a meta-analysis. Med Oncol. 2011; 28: 1004-11. doi: 10.1007/s12032-010-9594-0.

25. Yang L, Yang Y, Qin Q, Zhou A, Zhao J, Wang J, Shu C, Yuan X, Hu S. Evaluation of the optimal dosage of S-1 in adjuvant SOX chemotherapy for gastric cancer. Oncol Lett. 2015; 9: 1451-7. doi: 10.3892/ol.2014.2821.

26. Therasse P, Arbuck SG, Eisenhauer EA, Wanders J, Kaplan RS, Rubinstein L, Verweij J, Van Glabbeke M, van Oosterom AT, Christian MC, Gwyther SG. New guidelines to evaluate the response to treatment in solid tumors. European Organization for Research and Treatment of Cancer, National Cancer Institute of the United States, National Cancer Institute of Canada. J Natl Cancer Inst. 2000; 92: 205-16.

27. Chen L, Tian H, Chen J, He ZG, Tao SF, Lokesh G, Peng SY. Surgical management of gastric stump cancer: a report of 37 cases. J Zhejiang Univ Sci B. 2005; 6: 38-42. doi: 10.1631/jzus.2005.B0038.

28. Kollmannsberger C, Budach W, Stahl M, Schleucher N, Hehr T, Wilke H, Schleicher J, Vanhoefer U, Jehle 
EC, Oechsle K, Trarbach T, Boehlke I, Kanz L, et al. Adjuvant chemoradiation using 5-fluorouracil/folinic acid/ cisplatin with or without paclitaxel and radiation in patients with completely resected high-risk gastric cancer: two cooperative phase II studies of the AIO/ARO/ACO. Ann Oncol. 2005; 16: 1326-33. doi: 10.1093/annonc/mdi252.

29. Lin WL, Li DG, Chen Q, Lu HM. Clinical and experimental study of oxaliplatin in treating human gastric carcinoma. World J Gastroenterol. 2004; 10: 2911-5.

30. Liu B, Ying J, Luo C, Xu Q, Zhu L, Zhong H. S-1 combined with oxaliplatin as first line chemotherapy for Chinese advanced gastric cancer patients. Hepatogastroenterology. 2012; 59: 649-53. doi: 10.5754/hge11893.

31. Koizumi W, Takiuchi H, Yamada Y, Boku N, Fuse N, Muro K, Komatsu Y, Tsuburaya A. Phase II study of oxaliplatin plus S-1 as first-line treatment for advanced gastric cancer (G-SOX study). Ann Oncol. 2010; 21: 1001-5. doi: 10.1093/annonc/mdp464.

32. Louvet C, Andre T, Tigaud JM, Gamelin E, Douillard JY, Brunet R, Francois E, Jacob JH, Levoir D, Taamma A, Rougier P, Cvitkovic E, de Gramont A. Phase II study of oxaliplatin, fluorouracil, and folinic acid in locally advanced or metastatic gastric cancer patients. J Clin Oncol. 2002; 20: 4543-8.

33. Al-Batran SE, Atmaca A, Hegewisch-Becker S, Jaeger D, Hahnfeld S, Rummel MJ, Seipelt G, Rost A, Orth J, Knuth A, Jaeger E. Phase II trial of biweekly infusional fluorouracil, folinic acid, and oxaliplatin in patients with advanced gastric cancer. J Clin Oncol. 2004; 22: 658-63. doi: 10.1200/jco.2004.07.042.

34. Lordick F, Lorenzen S, Stollfuss J, Vehling-Kaiser U, Kullmann F, Hentrich M, Zumschlinge R, Dietzfelbinger H, Thoedtmann J, Hennig M, Seroneit T, Bredenkamp R, Duyster J, et al. Phase II study of weekly oxaliplatin plus infusional fluorouracil and folinic acid (FUFOX regimen) as first-line treatment in metastatic gastric cancer. Br J Cancer. 2005; 93: 190-4. doi: 10.1038/sj.bjc.6602697.

35. Lv F, Liu X, Wang B, Guo H, Li J, Shen L, Jin M. S-1 monotherapy as second line chemotherapy in advanced gastric cancer patients previously treated with cisplatin/ infusional fluorouracil. Int J Clin Exp Pathol. 2014; 7: 42749.

36. Kim GM, Jeung HC, Rha SY, Kim HS, Jung I, Nam BH, Lee KH, Chung HC. A randomized phase II trial of S-1oxaliplatin versus capecitabine-oxaliplatin in advanced gastric cancer. Eur J Cancer. 2012; 48: 518-26. doi: 10.1016/j.ejca.2011.12.017.

37. Oh SY, Kwon HC, Jeong SH, Joo YT, Lee YJ, Cho S, Kang MH, Go SI, Lee GW, Kim H, Kang JH. A phase II study of S-1 and oxaliplatin (SOx) combination chemotherapy as a first-line therapy for patients with advanced gastric cancer. Invest New Drugs. 2012; 30: 350-6. doi: 10.1007/s10637010-9507-2.

38. Park I, Lee JL, Ryu MH, Chang HM, Kim TW, Sym SJ, Lee SS, Jang G, Yoo C, Bae KS, Kang YK. Phase I/II and pharmacokinetic study of S-1 and oxaliplatin in previously untreated advanced gastric cancer. Cancer Chemother Pharmacol. 2010; 65: 473-80. doi: 10.1007/s00280-0091052-3.

39. Sakuramoto S, Sasako M, Yamaguchi T, Kinoshita T, Fujii M, Nashimoto A, Furukawa H, Nakajima T, Ohashi Y, Imamura H, Higashino M, Yamamura Y, Kurita A, et al. Adjuvant chemotherapy for gastric cancer with S-1, an oral fluoropyrimidine. N Engl J Med. 2007; 357: 1810-20. doi: 10.1056/NEJMoa072252. 